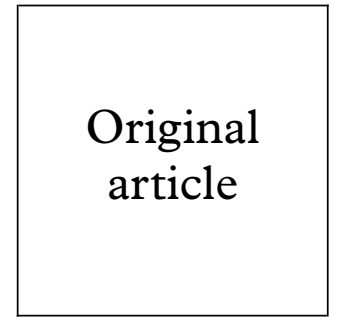

\section{Comparison of clinical, histological, and virological symptoms of HPV in HIV-1 infected men and immunocompetent subjects}

\author{
Olivier Aynaud, Dominique Piron, Renzo Barrasso, Jean-Dominique Poveda
}

Objective: We assessed the clinical, histological, and virological features of anogenital human papillomavirus (HPV) infection, according to their immune status in HIV-1 infected men, referred for an anogenital examination or treatment, in comparison with immunocompetent patients.

Methods: The study population comprised $33 \mathrm{HIV}-1$ infected heterosexual or homosexual men and 38 HIV negative men seen in a screening and treatment centre for anogenital HPV infections. All patients were examined with a colposcope. Biopsies were carried out on all subjects with anogenital lesions for histological studies and HPV detection by Southern blot.

Results: The HIV infected patients had a balanopreputial HPV infection in $70 \%$, anal in $30 \%$, and urethral in $37 \%$, while HIV negative patients had balanopreputial lesion in $72 \%$, anal in $26 \%$, and urethral in $16 \%$. Diffuse anogenital lesions were present in $33 \%$ of the HIV infected cases and in $10.5 \%$ of HIV negative cases $(\mathrm{p}<0.02)$. Among the HIV infected patients, the genital HPV lesions were condylomatous in $67.5 \%$ of the cases and dysplastic in $57 \%$. HIV negative patients had condylomatous lesions in $86 \%$ of the cases and dysplasic in $14 \%$. The condylomatous lesions of HIV infected patients had a low grade malignant histological aspect in $36 \%$ of the cases and high grade histological criteria were found in $22 \%$ of the dysplasias. Oncogenic HPVs were detected more frequently in HIV infected patients (35\% v 12\%) and more than one HPV type was found in $21.5 \%$ of cases. Neither the anogenital diffusion of the HPV lesions nor their morphological, histological, and virological features differed significantly in patient with CD4 cell counts $>$ or $<200 \times 10^{6} / 1$. In contrast, patients with CD 4 cell counts $<50 \times 10^{6} / 1$ had a higher risk of several types of HPVs and of developing a diffuse anogenital infection.

Conclusion: HIV-1 infected patients had an increased frequency of high grade anogenital dysplastic lesions and a higher frequency of HPV infection with multiple and diffuse sites of involvement. These characteristics of HPV infection were independent of the patients' immune status up to CD 4 cell counts $>50 \times 10^{6} / 1$ but showed an increased risk when the CD 4 cell count was $<50$ $\times 10^{6} / 1$. The higher frequency of diffuse anogenital infections among HIV infected men calls for rapid treatment, laser or surgery, given the association of histological features of intraepithelial neoplasia and the presence of multiple HPV infection sites which may be the consequence of immune disturbances, most of which are transmissible potentially oncogenic HPVs. (Sex Transm Inf 1998;74:32-34)

Keywords: HIV; human papillomavirus; squamous cell carcinoma; anogenital neoplasm

Department

Urology-Andrology,

Léopold Bellan

Hospital, 21 rue

Vercingétorix, 75014

Paris, France

O Aynaud

Anatomopathology Center, 19 rue de Passy 75016 Paris, France

D Piron

\section{Department of \\ Gynecology, \\ Bichat-Claude \\ Bernard Hospital, \\ Paris, France \\ R Barrasso}

Biology Center, Institut Pasteur, 52 rue de Docteur Roux 75015 Paris, France J-D Poveda

Correspondence to: Dr O Aynaud, 36 rue Desaix 75015, Paris, France.

\section{Introduction}

Human papillomaviruses (HPV) cause benign and preneoplastic anogenital lesions which are associated with HPVs 6,11 , and 42 (most condyloma acuminata and flat condyloma), or HPVs 16, 18, 31, 33, 35, and 39 (most preneoplastic lesions). ${ }^{1}$ It has been showed that immunodeficiency, whatever its cause, is associated with an increased frequency of HPV infection, suggesting that the expression of HPV may be modulated by host immune status. $^{2}$ In addition, HIV positive homosexual men with anal HPV infection appear to be at an increased risk of developing anorectal precancer. ${ }^{3}$ Thus, HPV associated lesions should be screened and the aim of this study was to determine the clinical, histological, and virological characteristics of HPV lesions in HIV-1 infected homosexual or heterosexual men attending an HPV screening centre for diagnosis or treatment, according to their immune status.

\section{Patients and methods}

Over 6 months, $27 \mathrm{HIV}-1$ infected men (17 heterosexual, 16 homosexual) and 38 HIV negative men (26 heterosexual, 12 homosexual) were referred for diagnosis or treatment of anogenital HPV infection, to our centre for laser treatment of recalcitrant lesions. All patients had cryotherapy and/or podophyllotoxin for at least 3 weeks. All patients underwent anopeniscopy with a colposcope (Zeiss OPMI99) before and after application of $5 \%$ acetic acid. Urethral lesions were detected during colposcopy with a Hartmann speculum visualising the first $20 \mathrm{~mm}$ of the urethra. ${ }^{4}$ Anuscopy was also performed during colposcopy. The clinical aspects of HPV infection are now well defined: exophytic lesions (condyloma acuminata, papulae) or macular/endophytic lesions (flat condyloma), and preneoplastic lesions (leucoplasic, erythroplastic, or pigmented). ${ }^{5}$ 
Table 1 Comparison of clinical, histological, and virological aspects of anogenital HPV infection in HIV-1 infected men and immunocompetent subjects

\begin{tabular}{|c|c|c|c|c|c|c|c|c|}
\hline & \multicolumn{8}{|c|}{ Anogenital location of $H P V$ lesions } \\
\hline & \multicolumn{2}{|c|}{ No of cases } & \multicolumn{2}{|c|}{ Balano-preputial (\%) } & \multicolumn{2}{|c|}{ Urethral (\%) } & \multicolumn{2}{|c|}{ Anal (\%) } \\
\hline & HIV+ & $H I V-$ & $H I V+$ & $H I V-$ & HIV+ & $H I V-$ & $H I V+$ & $H I V-$ \\
\hline & 27 & 38 & $19(70)$ & $27(71)$ & $10(37)$ & $6(16)$ & $8(30)$ & $10(26)$ \\
\hline \multicolumn{9}{|l|}{ Sexual habits: } \\
\hline Homosexual & 13 & 12 & $6(46)$ & $3(23)$ & $3(27)$ & $1(8)$ & $7(54)$ & $8(66)$ \\
\hline Heterosexual & 14 & 26 & $13(93)$ & $24(92)$ & $7(50)$ & $5(19)$ & $1(7)$ & $2(8)$ \\
\hline \multicolumn{9}{|l|}{ Clinical aspect: } \\
\hline Exophytic & 23 & 32 & $9(47)$ & $18(67)$ & $8(80)$ & $5(83)$ & $6(75)$ & $9(90)$ \\
\hline $\begin{array}{l}\text { Endophytic } \\
\text { Dysplasia }\end{array}$ & 2 & 3 & $2(10)$ & $3(11)$ & 0 & 0 & 0 & 0 \\
\hline Erythroplasties & 5 & 4 & $4(21)$ & $3(11)$ & $1(10)$ & 0 & 0 & $1(10)$ \\
\hline Blackish-brown & 2 & 1 & $1(5.5)$ & $1(4)$ & 0 & 0 & $1(12)$ & 0 \\
\hline Leucoplasia & 7 & 3 & $4(22)$ & $2(7)$ & $1(10)$ & $1(16)$ & $2(25)$ & 0 \\
\hline Diffuse infection & $9^{\star}$ & 4 & $8(42)$ & $2(7)$ & $1(10)$ & $1(6)$ & $3(37)$ & $1(10)$ \\
\hline \multicolumn{9}{|l|}{ Histological aspect: } \\
\hline Number of lesions & 37 & 43 & & & & & & \\
\hline Condyloma & 25 & 35 & $12(63)$ & $21(78)$ & $8(80)$ & $5(83)$ & $5(62)$ & $9(90)$ \\
\hline grade I neoplasia & $13 \dagger$ & 6 & $7(37)$ & $4(15)$ & $4(40)$ & $1(16)$ & $2(37)$ & $1(10)$ \\
\hline grade II-III/in situ & 8 & 2 & $6(31)$ & $2(7)$ & 0 & 0 & $2(25)$ & 0 \\
\hline \multicolumn{9}{|c|}{ Virological findings genotype SBH: } \\
\hline Number of lesions & 37 & 43 & & & & & & \\
\hline HPV 6/11 & $23 \ddagger$ & 31 & $12(63)$ & $17(63)$ & $6(60)$ & $5(83)$ & $5(62)$ & $9(90)$ \\
\hline HPV 42 & 2 & 3 & $2(11)$ & $3(11)$ & 0 & 0 & 0 & 0 \\
\hline HPV16 & $10 \ddagger$ & 4 & $6(31)$ & $2(7)$ & $1(10)$ & $1(16)$ & $3(37)$ & $1(10)$ \\
\hline HPV18 & $1 \ddagger$ & 1 & $1(5)$ & $1(4)$ & 0 & 0 & 0 & 0 \\
\hline HPV31/33/35/39 & $4 \ddagger$ & 0 & $4(22)$ & 0 & 0 & 0 & 0 & 0 \\
\hline HPV X & 4 & 4 & $1(5)$ & $4(15)$ & $1(10)$ & 0 & $2(25)$ & 0 \\
\hline
\end{tabular}

HIV+ = HIV infected; HIV- = negative; $\mathrm{SBH}=$ Southen blot hybridisation.

*Ano-urethro-preputial lesion in 1 case, ano-preputial lesion in one case.

†Condylomata + grade I intraepithelial neoplasia in nine cases.

$\ddagger$ Several types of HPV: co-infection in the same lesions: HPV $6+\mathrm{X}$ in one case, HPV $6+16$ in four cases, HPV $6+18$ in one case, HPV $6+31$ in one case, HPV $6+16+33+35$ in one case; HPV in different lesion from the same patient: HPV 6 and 39 , HPV 6 and $\mathrm{X}, \mathrm{HPV} 6+16$ and $\mathrm{X}$

HISTOLOGICAL EXAMINATION

All morphologically different HPV anogenital lesions were biopsied: 37 lesions in 27 HIV infected patients and 43 lesions among 38 HIV negative. Specimens were fixed in Carnoy for histological studies and cultured in Eagle's medium for virological analysis by means of molecular hybridisation (Southern blot). The biopsied HPV lesions were classified histologically as condylomatous or intraepithelial neoplasia (IN). ${ }^{5}$ The degree of intraepithelial neoplasia (grades I to III/in situ carcinoma) was judged on the degree of atypical cellular aspects and their topography within the epithelium as for cervical intraepithelial neoplasia. ${ }^{6}$

DETECTION OF HPV

All specimens for this study, HPV DNA sequences were detected at the Pasteur Institute by means of molecular hybridisation (Southern blot) with probes specific for HPV $6,11,42,16,18,33,31,35$, and 39 , also permitting the detection of HPV related viruses.

\section{STATISTICAL METHODS}

Associations between variables were examined by $\chi^{2}$ test for categorical variables. Odds ratio (OR) are presented for each risk factor and corresponding exact $95 \%$ confidence intervals (CI) were calculated. A p value $<0.05$ was considered significant.

\section{Results}

The mean age of the men was 32 (range 23-45 years). In the HIV infected group, the mean rate of CD 4 was $175 \times 10^{6} / 1$. Nine patients had
CD 4 cell counts $>200 \times 10^{6} / 1$, of whom three had counts $>400 \times 10^{6} / 1$, while 18 had CD 4 cell counts $<200 \times 10^{6} / 1$, and six with counts $<50 \times 10^{6} / 1$. In the HIV negative group the mean rate of CD4 was $986 \times 10^{6} / 1$ (range $\left.615-1714 \times 10^{6} / 1\right)$.

Among the $27 \mathrm{HIV}$ infected patients with clinical HPV lesions, 16 (59.3\%) already had these lesions diagnosed before serological diagnosis of HIV infection, in two cases $(7.4 \%)$ they were diagnosed at the same time as HIV seropositivity, while in nine cases $(33.3 \%)$ the HPV lesions appeared after serological diagnosis (range 40 months).

The HPV lesions were balanopreputial in 46 cases $(71 \%)$, anal in $18(28 \%)$, and urethral in $16(25 \%)$. In five cases ( $8 \%)$ the urethral lesions were not associated with HPV lesions at other sites. Their location according to sexual habits and HIV status is shown in table 1. HIV infected patients had two to three locations (urethralpreputial, urethral-anal, anal-urethral-preputial) in eight cases $(30 \%)$ and HIV negative in five cases $(13 \%)$, but the number of location of HPV lesions is independent of seropositivity $(\mathrm{p}<$ $0.10, \mathrm{OR}=2.77 ; 95 \% \mathrm{CI}=0.82-9.39$ ) as well as of sexual behaviour (homo/bisexual $12 \%$ and heterosexual $25 \%, \mathrm{p}<0.20, \mathrm{OR}=2.44 ; 95 \% \mathrm{CI}$ $=0.63-9.46$ ). However, a diffuse infection (total area $>4 \mathrm{~cm}^{2}$ ) was present in nine HIV infected cases $(33 \%)$ and four HIV negative cases $(10.5 \%)(\mathrm{p}<0.02, \mathrm{OR}=4.25 ; 95 \% \mathrm{CI}=1.22$ 14.8).

The clinical aspect was suggestive of condylomata in 60 cases $(75 \%)$ and preneoplastic lesions in 22 cases $(27.5 \%)$. HIV infected patients more often had clinically preneoplastic 
Table 2 Correlation among clinical, histological, and virological findings and immune status in HIV-1 men infected

\begin{tabular}{lllllll}
\hline & \multicolumn{5}{l}{ No of HIV+ patients with $H P V$ lesions $(\%)$, immune status $\left(C D 4\right.$ cell counts $\left.\times 10^{6} / l\right)$} \\
\cline { 2 - 7 } & $\begin{array}{l}\text { No of } \\
\text { cases }\end{array}$ & $\begin{array}{l}\text { CD4>200 } \\
9(33)\end{array}$ & $\begin{array}{l}200>C D 4<50 \\
12(45)\end{array}$ & $\begin{array}{l}\text { CD4 } 650 \\
6(22)\end{array}$ & Crude ratio & $95 \% C I$ \\
\hline Diffuse condylomatosis & 9 & $2(22)$ & $3(25)$ & $4(66)$ & $\mathrm{OR}_{1}=2.23(\mathrm{NS})$ & $\mathrm{OR}_{2}=6.4(\mathrm{p}<0.05)$ \\
High grade lesions & 8 & $2(22)$ & $3(25)$ & $3(50)$ & $\mathrm{OR}_{1}=1.75(\mathrm{NS})$ & $\mathrm{OR}_{2}=3.2(\mathrm{NS})$ \\
Oncogenic HPV & 13 & $4(44)$ & $5(41)$ & $4(66)$ & $\mathrm{OR}_{1}=1.25(\mathrm{NS})$ & $\mathrm{OR}_{2}=2.7(\mathrm{NS})$ \\
Several types of HPV & 10 & $2(22)$ & $4(33)$ & $4(66)$ & $\mathrm{OR}_{1}=2.8(\mathrm{NS})$ & $\mathrm{OR}_{2}=5(\mathrm{p}<0.10)$ \\
\hline
\end{tabular}

$\mathrm{OR}_{1}=$ odd ratio between the patients with CD4 cell counts $>$ and $<200 / \times 10^{6} / 1$

$\mathrm{OR}_{2}=$ odd ratio between the patients with CD4 cell counts $>$ and $<50 / \times 10^{6} / 1$.

lesions $(52 \% v 21 \%, \mathrm{p}<0.01)$ alone or associated with condyloma. Among HIV infected, in six cases $(26 \%)$ the condyloma acuminata were hyperkeratinised and in four cases (11\%) several clinical aspects were observed (exophytic + leucoplastic, exophytic + erythroplastic, leucoplastic + erythroplastic)..$^{5}$

Histology confirmed, among HIV infected patients, the intraepithelial neoplasias (IN) were low grade (IN I) in 13 cases (35\%), and associated with a condyloma in nine cases (two anal, five preputial, and two urethral lesions). The risk of presenting high grade lesions was increased in HIV infected patients $(22 \% v 5 \%$, $\mathrm{OR}=5.65 ; 95 \% \mathrm{CI}=1.31-25.3)$.

The 80 biopsy specimens were analysed virologically (table 1 ). Southern blot revealed HPV DNA sequences of type 6/11 in 54 cases $(67.5 \%)$ and potentially oncogenic HPVs were detected in 18 cases $(22.5 \%)$ with a frequency of $78 \% \mathrm{HPV}$ 16. Oncogenic HPVs were detected more often in the lesions of HIV infected subjects $(35 \%$ v $12 \%, \mathrm{p}<0.02)$. Among HIV infected subjects a co-infection with several HPVs in the same lesion was discovered in seven cases (9\%). In three cases $(8.5 \%)$ we observed several types of HPVs in different lesions from the same patient. HPVs $31,33,35$, and 39 were detected in patients with CD4 cell counts $<200 \times 10^{6} / 1$.

Diffuse infection, high grade intraneoplasia lesions, oncogenic HPVs, and several types of HPV DNA were related to the CD4 cell counts, only $<50 \times 10^{6} / 1$ in HIV positive patients (table 2).

\section{Discussion}

In this study, among HIV infected patients, $33 \%$ developed HPV lesions 36 to 48 months after becoming seropositive. Most $(78 \%)$ of the patients who developed HPV lesions after the diagnosis of HIV infection had CD4 cell counts $<200 \times 10^{6} / 1,57 \%$ of whom had counts $<50 \times 10^{6} / 1$. Since genital HPV infection is sexually transmitted, the presence of these HPV lesions after the diagnosis of HIV infection in patients, most of whom are immunodepressed, points to a latent HPV infection reactivated by the immunodepression, more than to a recent sexual transmission signalling the non-use of condoms.

Clinical screening for HPV lesions in the anogenital sphere must also include both meatopeniscopy (non-invasive) and anuscopy, regardless of sexual behaviour. ${ }^{8}$ However, HIV positivity increases the frequency of multiple location of HPV lesions, urethropreputial in homo/bisexual men and only urethral in heterosexual men.

Among HIV infected patients, the exophytic condylomatous lesions were frequently associated with low grade intraepithelial neoplasia (33\%) and oncogenic HPVs (26\%), suggesting that the onset of oncogenic HPV associated lesions is facilitated by immunodeficiency. In the same way, the increase of high grade intraepithelial neoplasia (IN II-III/in situ) $(22 \%)$ and of a higher frequency $(15 \%)$ of HPV types 31, 33, 35, and 39 among the HIV positive patients suggests the involvement of immunological cofactors in the development of certain types of HPV. ${ }^{9} \mathrm{HIV}$ facilitates either the activation of recently acquired HPVs or the reactivation of latent infection, or both.

Potential oncogenic HPVs associated intraepithelial neoplasia and several types of HPV was statistically more frequent in patients with CD 4 cell counts $<50 \times 10^{6} / 1$. The absence of a significant difference between patients with CD 4 cell counts $>$ and $<200 \times 10^{6} / 1$ in terms of clinical, histological, and virological signs of HPV infection does not predispose to a wider diffusion of HPV infections or the type of viral DNA among HIV seropositive patients.

1 Smotkin D, Prokoph H, Wattstein F. Oncogenic and non-oncogenic human genital papillomavirusgenerates the E7 mRNA by different mechanisms. F Virol 1989;63:1441-7.

2 Alloub MI, Barr BBB, McLaren KM, et al. Human papilloAlloub MI, Barr BBB, McLaren KM, et al. Human papillomavirus infection and cervical intraepithelial neop

3 Frazer IH, Medley G, Crapper RM, Brown TC, Mackay IR. Association between anorectal dysplasia, human papillomavirus and human immunodeficiency virus infection in homosexual men. Lancet 1986;2:657-60

4 Aynaud O, Casanova J-M, Barrasso R. Nouvelles techniques de détection et traitement des condylomes uréthraux chez l'homme: à propos de 2000 cas. F Urol (Paris) 1991;97:29-

5 Aynaud O, Ionesco M, Barrasso R. Penile intraepithelial neoplasia: specific clinical features correlate with histologic and virologic findings. Cancer 1994;74:1762-7.

6 Fu YS, Huang I, Beaudenon S, et al. Correlative study of human papillomavirus DNA, histopathology, and morphometry in cervical cervical condyloma and intraepithelial phometry in cervical cervical condyloma and intra

Barrasso R, de Brux J, Croissant O, Orth G. High prevalence of papillomavirus associated penil intraepitheprevalence of papillomavirus associated penil intraepithe-
lial neoplasia in sexual partners of women with cervical intraepithelial neoplasia. N Engl f Med 1987;317:916-23.

8 Van Doornum GJJ, Prins M, Juffermans LHJ, et al. Regiona distribution and incidence of human papillomavirus infections among heterosexual men and women with multiple sexual partners: a prospective study. Genitourin Med 1994; 70:240-6.

9 Williams AB, Darragh TM, Vranizan K, et al. Anal and cervical human papillomavirus infection and risk of anal and cervical epithelial abnomalities in human immunodeficiency virus-infected women. Obstet Gynecol 1994;83:205-11. 